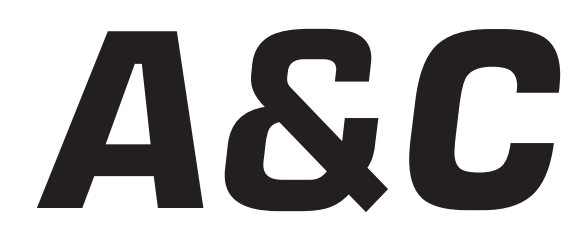

Revista de Direito Administrativo \& Constitucional

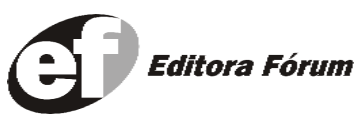

A\&C R. de Dir. Administrativo e Constitucional, Belo Horizonte, ano 5, n.19, p. 1-254, jan./mar. 2005 


\section{A\&C REVISTA DE DIREITO ADMINISTRATIVO E CONSTITUCIONAL}

\section{IPDA}

Instituto Paranaense

de Direito Administrativo

Direção Geral

Romeu Felipe Bacellar Filho

Direção Editorial

Paulo Roberto Ferreira Motta

Direção Executiva

Emerson Gabardo

Conselho de Redação

Edgar Chiuratto Guimarães

Adriana da Costa Ricardo Schier

Célio Heitor Guimarães

Conselho Editorial

Adilson Abreu Dallari

Alice Gonzáles Borges

Carlos Ari Sundfeld

Carlos Ayres Britto

Carlos Delpiazzo

Cármen Lúcia Antunes Rocha

Celso Antônio Bandeira de Mello

Clèmerson Merlin Clève

Clóvis Beznos

Enrique Silva Cimma

Eros Roberto Grau

Fabrício Motta

Guilhermo Andrés Muñoz (in memoriam)

Jaime Rodríguez-Arana Muñoz

Jorge Luís Salomoni
José Carlos Abraão
José Eduardo Martins Cardoso

José Luís Said

José Mario Serrate Paz

Juan Pablo Cajarville Peruffo

Juarez Freitas

Julio Rodolfo Comadira

Luís Enrique Chase Plate

Lúcia Valle Figueiredo

Manoel de Oliveira Franco Sobrinho

(in memoriam)

Marçal Justen Filho

Marcelo Figueiredo

Márcio Cammarosano

Maria Cristina Cesar de Oliveira
Nelson Figueiredo

Odilon Borges Junior

Pascual Caiella

Paulo Eduardo Garrido Modesto

Paulo Henrique Blasi

Paulo Neves de Carvalho (in memoriam)

Paulo Ricardo Schier

Pedro Paulo de Almeida Dutra

Regina Maria Macedo Nery Ferrari

Rogério Gesta Leal

Rolando Pantoja Bauzá

Sérgio Ferraz

Valmir Pontes Filho

Yara Stropa

Weida Zancaner

\footnotetext{
A246 A\&C Revista de Direito Administrativo e Constitucional. ano 3, n. 11, jan./mar. 2003. Belo Horizonte: Fórum, 2003.

Trimestral

ano 1, n.1, 1999 até ano 2, n.10, 2002 publicada pela Editora Juruá em Curitiba

ISSN: 1516-3210

1. Direito Administrativo. 2. Direito Constitucional. I. Fórum.
}

CDD: 342 CDU: 33.342

(c) Editora Fórum Ltda. 2005

Todos os direitos reservados. É proibida a reprodução total ou parcial, de qualquer forma ou por qualquer meio eletrônico ou mecânico, inclusive através de processos xerográficos, de fotocópias ou de gravação, sem permissão por escrito do possuidor dos direitos de cópias (Lei $n^{\circ}$ 9.610, de 19.02.1998).

Editora Fórum Ltda

Av. Afonso Pena, 2770 - 15\%16ªndar - Funcionários

CEP 30130-007 - Belo Horizonte/MG - Brasil

Tel.: 08007043737

Internet: www.editoraforum.com.br

e-mail: editoraforum@editoraforum.com.br
Editor responsável: Luís Cláudio Rodrigues Ferreira Projeto gráfico e diagramação: Luis Alberto Pimenta Revisora: Olga M. A. Sousa

Pesquisa jurídica: Fátima Ribeiro - OAB/MG 74868

Bibliotecária: Nilcéia Lage de Medeiros

CRB 1545/MG 6a região

Os conceitos e opiniões expressas nos trabalhos assinados são de responsabilidade exclusiva de seus autores.

Impressa no Brasil / Printed in Brazil

Distribuída em todo Território Nacional 


\title{
A Natureza Jurídica da Relação de Trabalho entre o Estado e seus Agentes no Direito Administrativo Francês
}

\author{
Raquel Dias da Silveira \\ Mestra e Doutoranda em Direito Administrativo pela UFMG. Professora de Direito Administrativo \\ e Teoria do Estado na Universidade de Uberaba (Minas Gerais). Advogada
}

\begin{abstract}
Sumário: Introdução - 1 Função Pública - 1.1 Breves comentários sobre a noção de Função Pública - 1.2 Análise histórica do tratamento legal da matéria - 2 A classificação do pessoal da Administração Pública na França 2.1 Agentes públicos - 2.1.1 Agentes públicos funcionários - 2.1.2 Agentes públicos não funcionários - 2.2 Agentes contratados pelo regime de Direito Privado - 3 Estudo sobre a natureza jurídica do vínculo de trabalho entre o Estado e o agente na França - 3.1 Regime estatutário ou legal - 3.2 Regime contratual - Conclusão - Referências
\end{abstract}

\section{Introdução}

O presente trabalho visa tratar da natureza jurídica da relação de trabalho entre o Estado e seus agentes no Direito Administrativo francês, ao longo de três itens. No primeiro, serão feitas breves observações sobre a Função Pública francesa, no sentido de melhor introduzir o tema. A seguir, será realizada uma análise histórica do tratamento legal da matéria. No segundo, será apreciada a classificação dos agentes franceses, com o intuito de facilitar a compreensão dos regimes jurídicos que lhes cercam. O tema central do trabalho, será tratado no terceiro item, onde se demonstrarão as características e distinções entre o regime estatutário ou legal e o regime contratual do pessoal da Administração Pública na França.

Sem a menor pretensão de esgotar o assunto relacionado ao tema, almeja-se, ao final, comparar o sistema adotado na França com o Direito Administrativo brasileiro e demonstrar eventual evolução já conquistada pelo Direito francês, que sirva de paradigma para maior estudo e melhor doutrinamento da matéria no Brasil.

\section{Função Pública}

\subsection{Breves comentários sobre a noção de Função Pública}

Indubitavelmente, a noção de Função Pública reflete a noção de Estado. Na França, desde a consagração do Estado de Direito, as diversas formas de arbítrio de poder, até então, facilmente, praticadas pela 
Administração Pública, bem como a consagração de interesses particulares, em detrimento de outros, passaram a ceder lugar para o dever estatal de consecução do bem comum.

Surge, portanto, o princípio da supremacia do interesse público como um dos grandes pilares do chamado regime jurídico administrativo, exorbitante do Direito comum.

De conseguinte, tem-se, como instrumento de realização dos mais diversos interesses da comunidade, o exercício de Função pelos agentes estatais que, antes de serem titulares de qualquer direito subjetivo ao cargo, na verdade, assumem o encargo, a obrigação, o dever jurídico de bem desenvolver as funções que lhes são afetas.

Nessa senda, o exercício de Função Pública, na França, exige do indivíduo vocação (pois mantém-se a idéia de que o Estado não é um empregador qualquer), aptidões particulares e uma formação apropriada ao encargo assumido.

Especialmente adaptado à missão pública, o funcionário deve lhe consagrar toda a sua vida ativa. Em contrapartida, ele se beneficia de uma garantia contra ruptura abusiva do seu vínculo profissional e pode esperar um desenvolvimento, cada vez maior, de sua carreira, em termos de qualificação e rendimentos.

No sentido estrito, explica Laubadère, Venezia e Gaudemet, ${ }^{1}$ Função Pública corresponde ao estatuto dos funcionários propriamente dito, que constitui um conjunto rígido de regras de Direito Público e representa o máximo de previsões de exigências e garantias aplicáveis ao serviço público, embora não se aplique à totalidade do pessoal da Administração Pública.

No tocante à concepção estrita de Função Pública, é de bom alvitre, desde logo, ressaltar a existência de uma diversidade de estatutos de funcionários na França, que podem, inclusive, se aplicar conjuntamente.

Isso se deve a uma tendência verificada em grande parte do mundo, mesmo nos chamados Estados Unitários, como é o caso da França, de descentralização do poder, entendendo-se que as entidades locais possuem melhor condição de gerir os interesses da coletividade.

Assim, a França é dividida em 26 Regiões e 100 Departamentos, com competência restrita às respectivas circunscrições de executar as políticas públicas decididas em nível nacional e aplicar ou fazer aplicar os próprios regulamentos.

\footnotetext{
1 LAUBADÈRE, André de; VENEZIA, Jean-Claude; GAUDEMET, Yves. Traité de Droit Administratif. Tome 2. 10. ed. Paris: LGDJ, 1995, p. 17.
}

A \& C R. de Dir. Administrativo e Constitucional, Belo Horizonte, ano 5, n. 19, p. 97-113, jan./mar. 2005 
De conseguinte, a composição da Função Pública francesa reflete a organização político-administrativa do país. Porquanto unificada sob um estatuto denominado geral, a Função Pública encontra-se subdividida em três grandes categorias: a Função Pública do Estado (compreendida em todo o território nacional), a Função Pública das coletividades territoriais (compreendida no âmbito das Regiões, dos Departamentos e das Comunas) e a Função Pública hospitalar.

Ainda, o Estado francês pode delegar, no todo ou em parte, a uma pessoa jurídica de Direito Público, distinta dele (pessoa moral), a concepção e/ou a execução de políticas públicas. Para tanto, essas pessoas de Direito Público são dotadas de autonomia financeira e competência para recrutar o seu pessoal, permanecendo, entretanto, sob a tutela de determinado ministério que orienta a sua estratégia de ação, fiscaliza e controla a sua gestão e avalia os seus resultados. São os casos dos estabelecimentos públicos de caráter administrativo, dos estabelecimentos públicos de caráter industrial e comercial, dos estabelecimentos públicos de caráter científico e tecnológico e dos estabelecimentos públicos de caráter científico, cultural e profissional.

Não é, todavia, necessário, nem oportuno, que todo o pessoal da Administração Pública seja regido pelo Direito Público; um estatuto de Direito Privado pode ser, em certas ocasiões, mais conveniente a alguns agentes.

Como em outros institutos de Direito Administrativo, tais como contratos e domínios públicos (bens públicos), pode perfeitamente existir, no que concerne à Função Pública francesa - idéia essa que também inspira a concepção de agentes no Brasil — regras de Direito Privado, ao lado das de Direito Público.

\subsection{Análise histórica do tratamento legal da matéria}

Em 1901, Maurice Hauriou já definia a situação jurídica dos funcionários na França, no sentido de que os funcionários públicos não usufruíam de "status", isto é, uma situação jurídica estabelecida, pois se encontravam submetidos a um regime de polícia.

Praticamente, nenhuma lei ou decreto regulava a sua situação, que dependia do poder discricionário do ministro a cuja pasta se encontravam vinculados e em regime de subordinação.

A essa regra existiam, à época, algumas exceções, como a dos oficiais,

A \& C R. de Dir. Administrativo e Constitucional, Belo Horizonte, ano 5, n. 19, p. 97-113, jan./mar. 2005 
regulados pela lei de 19 de maio de 1834, e a dos chamados magistrados "du siège”, que são os juízes de carreira, responsáveis pela jurisdição comum, ${ }^{2}$ regidos pela lei de 30 de agosto de 1883 . Vale ressaltar, ainda, o caso dos funcionários do ensino, como os professores do ensino superior, regulados pela lei de 27 de fevereiro de 1880 (com as alterações da lei de 10 de julho de 1896), e os professores do ensino secundário, regulados pela lei de 27 de fevereiro de 1880 .

Destarte, a inexistência de um estatuto geral dos funcionários públicos na França incitava, freqüentemente, o Conselho de Estado a intervir nas relações envolvendo funcionários públicos e Estado, para condenar os abusos cometidos por autoridades hierárquicas.

Começou-se a elaborar, desde então, um estatuto jurisprudencial, especialmente em matéria de recrutamento e disciplina, destinado a preencher as lacunas resultantes da carência legislativa e regulamentar.

Essa intervenção do juízo administrativo teve por efeito indutivo rejeitar, por completo, a tese de que os funcionários se encontravam perante a Administração numa situação contratual.

Entendeu, a partir daí, o Conselho de Estado francês que os funcionários, independentemente do seu escalão, mantinham com a Administração uma relação jurídica de Direito Público. A solução adotada, à época, prepondera, como se verá mais adiante, até os nossos dias.

Em 14 de setembro de 1941, foi elaborado o primeiro estatuto dos funcionários franceses, que, com forte influência do Direito alemão, insistia na autoridade dos superiores hierárquicos, na obediência e fidelidade dos subordinados, na impossibilidade de recrutamento de pessoas de origem judia ou pertencente a qualquer sociedade secreta e na proibição de ingresso de mulheres na carreira.

Em abril de 1945, após os anos de guerra e invasão, foi criada a Missão Provisória de Reforma da Função Pública, presidida por Michel Debré, inspirada pela vontade de renovação da Administração Pública francesa.

A reforma culminou com o ordenamento de 9 de outubro de 1945, que, entre outras coisas, criou a Escola Nacional de Administração, um Conselho permanente da Função Pública (que marcou o início do reconhecimento informal do direito de sindicalização dos funcionários) e um

\footnotetext{
2 Vale lembrar a existência, na França, da dualidade de jurisdição, diferenciando a jurisdição comum da jurisdição especializada em matéria administrativa, a cargo do Conselho de Estado, por força de interpretação estrita do princípio da separação dos poderes.
} 
corpo interministerial de administradores civis.

Em 27 de março de 1946, foi criado um outro estatuto, com a aprovação de representantes das organizações de funcionários confederados e cristãos da Comissão Superior da Função Pública e do Conselho de Estado. Entre as inovações importantes deste estatuto, destacaram-se o reconhecimento formal e integral do direito de sindicalização aos funcionários; a proclamação da igualdade entre os sexos, para efeitos de ingresso no serviço público, e a garantia expressa de licença para tratamento de saúde e aposentadoria.

Assim, foi sendo, gradativamente, restituído todo o prestígio da Função Pública francesa. Contudo, continuou excluído da órbita de abrangência da supracitada lei o pessoal comum da Administração, regidos pela lei de 28 de abril de 1952; os militares, regidos pela lei de 13 de julho de 1972, e os magistrados, regidos pela lei de 22 de novembro de 1958.

A partir daí, a concepção francesa de Função Pública começou a se repousar sobre três grandes princípios: igualdade de acesso aos empregos públicos, independência dos funcionários com relação ao poder político e tratamento dos funcionários compatível com a cidadania, isto é, com pleno e integral respeito a seus direitos.

Em 4 de fevereiro de 1959, promulgou-se um outro estatuto, posteriormente derrogado pela lei de 11 de janeiro de 1984, que, assim como a legislação anterior, se aplicava apenas ao pessoal titular de emprego permanente. ${ }^{3}$ Os magistrados, militares, funcionários do setor hospitalar e funcionários das assembléias parlamentares continuaram regidos por estatutos próprios.

\section{A classificação do pessoal da Administração Pública na França 2.1 Agentes públicos}

A expressão agentes públicos, na França, corresponde ao conjunto de pessoas físicas que mantêm com o Estado relação de trabalho, regida pelo Direito Público.

Consoante Laubadère, Venezia e Gaudemet, ${ }^{4}$ a situação jurídica dos agentes públicos está longe de ser homogênea, todavia um certo número de princípios comuns de Direito Público são aplicados ao conjunto desses agentes.

3 Essa característica da permanência do funcionário no emprego resulta da consagração de importante princípio originário do Direito francês, a continuidade do serviço público.

4 LAUBADÈRE, André de; VENEZIA, Jean-Claude; GAUDEMET, Yves. Traité de Droit Administratif. Tome 2. 10. ed. Paris: LGDJ, 1995, p. 18. 
No que tange à competência para apreciar litígios envolvendo agentes públicos na França, por exemplo, esta pertence à jurisdição administrativa.

Desde 1954, a jurisprudência do Conselho de Estado e do Tribunal de Conflitos tem estabelecido um critério único a uma pluralidade e combinação de variáveis características desses agentes, de modo a qualificar a função dos agentes públicos por um caráter durável e não episódico ou ocasional.

A esta característica, deve-se acrescentar, ainda, a identidade das condições de recrutamento, o regime disciplinar, o modo de remuneração, a participação direta na execução de serviço público e a presença de cláusulas exorbitantes (no caso de agentes ligados ao Estado por meio de contrato de Direito Público).

\subsubsection{Agentes públicos funcionários}

Os agentes públicos chamados funcionários, segundo as lições de Laubadère, Venezia e Gaudemet, ${ }^{5}$ além de se submeterem ao conjunto de regras aplicáveis a todo gênero agentes públicos (submissão ao Direito Administrativo e à competência da jurisdição administrativa francesa), regemse por um corpo de regras mais particulares, que são as regras da Função Pública "stricto sensu".

As regras da Função Pública "stricto sensu", ou seja, o estatuto geral dos funcionários públicos da França, aplica-se concomitantemente com os estatutos específicos de cada categoria de agentes, podendo estes últimos regulamentos, inclusive, em determinados casos, derrogar a norma geral.

A despeito de, em determinadas circunstâncias, tais como a que ocorre na parte do Código Penal relativa a crimes praticados por funcionários, a expressão funcionário público possa ser aplicada indiscriminadamente, como correspondente ao conjunto de todos os agentes públicos, anotam os supracitados autores ${ }^{6}$ que o interesse maior concernente à noção de funcionário decorre da aplicação conjunta de diversos estatutos da Função Pública (o geral e os específicos de cada categoria).

Logo, para se saber qual regra de Direito figurante em um estatuto é aplicada a um agente determinado, será necessário indagar, antes de tudo, a qualidade ou o tipo específico do funcionário em exame.

Nesses casos, quando se trata de funcionários com estatutos 5 LAUBADĖRE, André de; VENEZIA, Jean-Claude; GAUDEMET, Yves. Traité de Droit Administratif. Tome 2. 10. ed. Paris: LGDJ, 1995, p. 24.

6 LAUBADÈRE, André de; VENEZIA, Jean-Claude; GAUDEMET, Yves. Traité de Droit Administratif. Tome 2. 10. ed. Paris: LGDJ, 1995, p. 25. 
próprios, a jurisprudência tem entendido que a eles também se aplicam certas regras e princípios do estatuto geral, notadamente, no que tange aos direitos e obrigações dos funcionários públicos.

A jurisprudência administrativa tem, ainda, progressivamente, deduzido a definição e as características do funcionário público no reconhecimento dessa qualidade ao indivíduo investido em um cargo permanente no serviço público. ${ }^{7}$ A mesma idéia foi adotada e reproduzida pelos estatutos de 1946, 1959 e 1984.

Depreende-se do artigo $2^{\circ}$ da lei $\mathrm{n}^{\circ} 84-16$, de 11 de janeiro de 1984, concernente à Função Pública do Estado, que funcionário público é o indivíduo nomeado para o exercício de um emprego permanente, em tempo integral, e titular de um grau de hierarquia das Administrações centrais do Estado, dos Serviços exteriores e dos estabelecimentos públicos. ${ }^{8}$

Porém, os estatutos das funções públicas territoriais e hospitalares (lei $n^{\circ} 84-53$, de 26 de janeiro de 1984 e lei nº 86-33, de 9 de janeiro de 1986, respectivamente) deixaram de mencionar a exigência de trabalho em tempo integral, vez que os mesmos também acolhem, na noção de funcionário, os titulares de cargo público, que trabalham em regime de meia jornada de tempo.

Laubadère, Venezia e Gaudemet ${ }^{9}$ apontam como a principal característica da definição de funcionário a permanência no emprego, o que os diferencia dos agentes temporários, e a integração em uma hierarquia administrativa.

Para os autores, é necessário entender essa permanência não apenas com relação ao emprego ocupado, mas também no que atine à ocupação desse emprego. Em outras palavras, urge que o agente ocupe a título permanente um emprego que seja, por si mesmo, permanente.

René Chapus, ${ }^{10}$ por sua vez, identifica os agentes públicos, tidos como funcionários, como aqueles que são os titulares da Função Pública por eles exercida, em contraposição aos não funcionários, a seguir vistos,

\footnotetext{
Adverte Frédérique BERTRAND, in Fonction Publique. Revue Française de Droit Administrative. 3 (4) jul.ago. 1987, p. 554, que, apesar da reafirmação periódica no Direito francês do princípio segundo o qual os empregos permanentes do Estado e de seus estabelecimentos públicos devem ser ocupados por funcionários, a Administração nunca tem renunciado, totalmente, à prerrogativa de recrutar agentes não titulares, para atender a necessidades ocasionais e sazonais do serviço público.

8 Percebe-se, na França, a despeito da distinção entre relação de trabalho regida pelo Direito Público e relação de trabalho regida pelo Direito Privado, que os vocábulos cargo e emprego são aplicados, indiscriminadamente, pelos autores, à diferença do Direito brasileiro.

9 LAUBADÈRE, André de; VENEZIA, Jean-Claude; GAUDEMET, Yves. Traité de Droit Administratif. Tome 2.

10. ed. Paris: LGDJ, 1995, p. 26.

${ }^{10}$ CHAPUS, René. Droit Administratif General. Tomo II. 9. ed. Paris: Montcherestien, 1996, p. 38.
} 
que se encontram investidos em determinada função, em razão de certas circunstâncias, por um dado período de tempo. Logo, para o autor, a principal característica dos funcionários públicos seria a titularidade que os mesmos exercem sobre o cargo que ocupam.

Segundo Chapus, ${ }^{11}$ é a titularidade da função que confere ao funcionário um certo "status", isto é, uma situação estável, protegida pela "garantia do emprego". ${ }^{12}$

Complementando os ensinamentos de Laubadère, Venezia e Gaudemet, explica Chapus ${ }^{13}$ que o recrutamento do agente via contrato exclui a qualidade de funcionário, pois não há funcionário nomeado por contrato, de acordo com a doutrina francesa, sob a lógica do Estado de Direito (sobretudo em face dos princípios da legalidade e igualdade, que impõem uma seleção mediante concurso), construída a partir do estatuto de 1946.

Para explicar o trabalho em meia jornada de tempo pelos funcionários públicos ocupantes de funções territoriais e hospitalares, Laubadère, Venezia e Gaudemet ${ }^{14}$ assinalam que a ocupação permanente não significa a tempo completo.

Não bastasse, nesses casos, a existência de estatutos específicos para os agentes territoriais e hospitalares, a lei de 24 de julho de 1994, veio, nesse tocante, modificar o estatuto geral de 1984 e organizar o tempo de trabalho, inclusive o trabalho em tempo parcial.

Outra nota importante para a compreensão de funcionário público é que todos eles, dentro da hierarquia administrativa, se organizam na idéia de "corpo" da Administração Pública, que, recentemente, veio substituir a idéia de "quadro", ${ }^{15}$ no Direito Administrativo francês.

\subsubsection{Agentes públicos não funcionários}

À diferença dos agentes considerados funcionários, que são uniformemente submetidos a uma situação legal ou regulamentar de Direito Público, a definição de agente não funcionário põe em relevo a existência de regimes jurídicos diversos.

Certos agentes não funcionários encontram-se, como os funcio11 CHAPUS, René. Droit Administratif General. Tomo II. 9. ed. Paris: Montcherestien, 1996, p. 39.

12 O que, sem dúvida, representa importante avanço com relação à idéia já explicitada, anteriormente preconizada por HAURIOU

13 CHAPUS, René. Droit Administratif General. Tomo II. 9. ed. Paris: Montcherestien, 1996, p. 40.

${ }^{14}$ LAUBADÈRE, André de; VENEZIA, Jean-Claude; GAUDEMET, Yves. Traité de Droit Administratif. Tome 2.

10. ed. Paris: LGDJ, 1995, p. 26.

15 Tal substituição representa importante avanço do Direito Administrativo francês no sentido de que a Administração Pública deve funcionar como um sistema harmônico dos órgãos que a compõem. 
nários, em uma situação jurídica legal ou regulamentar. Outros são submetidos a uma situação jurídica contratual.

A grande dúvida que se põe, acerca da questão, é se os agentes públicos não funcionários são contratados, exclusivamente, pelo Direito Público, ou se há também a possibilidade de se firmar entre a Administração e um agente não funcionário um contrato de Direito Privado.

Da interpretação que se faz de parte da doutrina, o tema aparece, pelo menos nesse primeiro momento do desenvolvimento do trabalho, tratado de maneira contraditória, como o fazem Laubadère, Venezia e Gaudemet ${ }^{16}$ que, ao mesmo tempo em que admitem que se aplicam aos agentes não funcionários os contratos de Direito Público e de Direito Privado, anteriormente, ao classificarem os agentes públicos em funcionários e não funcionários, na definição de agentes públicos, os autores afirmam ser aqueles regidos pelo Direito Público.

Para Louis Rolland, ${ }^{17}$ esses agentes não funcionários se diferenciam de simples particulares colaboradores do Estado pelo fato de fazerem parte da Administração. Já com relação aos agentes funcionários, a diferença reside em que os não funcionários não ocupam empregos permanentes e sua função na Administração Pública não se encontra prevista nos quadros administrativos. Esses agentes são, muitas vezes, denominados, de forma geral e imprecisa, de estagiários ou auxiliares do Estado.

Os estagiários são os agentes que possuem vocação normal de serem titulares na carreira. Podem se classificar como estagiários de Direito comum e estagiários por determinação da lei.

Os primeiros são os nomeados para o exercício de emprego permanente, cuja titularidade ainda carece de algum pronunciamento. Segundo o decreto de 7 de outubro de 1994, são pessoas que possuem vocação para serem titulares de determinada função, após determinado período probatório ou de formação.

Já os estagiários por determinação da lei são os estudantes de diversas grandes escolas preparatórias para o exercício de Função Pública existentes na França, a exemplo da renomada e conhecida Escola Nacional de Administração.

No que concerne aos auxiliares, esses agentes devem, normalmente, ser recrutados para o preenchimento de empregos não suscetíveis de serem ${ }^{16}$ LAUBADÈRE, André de; VENEZIA, Jean-Claude; GAUDEMET, Yves. Traité de Droit Administratif. Tome 2. 10. ed. Paris: LGDJ, 1995, p. 35.

${ }_{17}$ ROLLAND, Louis. Précis de Droit Administratif. 10. ed. Paris: Dalloz, 1951, p. 121.

A \& C R. de Dir. Administrativo e Constitucional, Belo Horizonte, ano 5, n. 19, p. 97-113, jan./mar. 2005 
ocupados por funcionários, isto é, empregos correspondentes a tarefas provisórias ou ocasionais, empregos estranhos à especialidade do corpo de funcionários então existente.

Anota Chapus, ${ }^{18}$ entretanto, que, com a extensão das tarefas da Administração Pública, a partir da Guerra de 1914 a 1918 (período que coincide com a adoção do Estado Social na França), essa antiga regra adotada para recrutamento de auxiliares foi-se perdendo de vista, verificandose, atualmente, a nomeação de inúmeros auxiliares para desempenhar obrigações típicas de funcionários públicos.

A nomeação de funcionários não titulares para desempenhar funções típicas de funcionários públicos foi juridicamente viabilizada pela lei $\mathrm{n}^{\circ}$ 83-481, de 11 de junho de 1983, definindo as condições segundo as quais devem ser previstos os empregos civis permanentes do Estado e de seus estabelecimentos públicos administrativos e autorizando a nomeação de agentes não titulares para a ocupação desses empregos.

Entretanto, o legislador de 1983, como bem aduz Frédérique Bertrand, ${ }^{19}$ cuidou de definir, ao máximo, as possibilidades de derrogação da regra de ocupação de empregos permanentes do Estado por funcionários públicos, excepcionando, apenas, quatro situações segundo as quais se admite a contratação de não titulares.

A primeira dessas exceções refere-se à ocupação de empregos que constituem categorias bem definidas e facilmente isoladas, tais como empregos superiores cuja nomeação fica a cargo da discrição do Governo e empregos de professores pesquisadores de estabelecimentos de ensino superior e de pesquisa, confiados a pessoas convidadas ou associadas. Esses empregos são habitualmente ocupados por uma categoria de agentes, fixada por decreto, que possui seu próprio estatuto, como o caso dos operários, pessoal médico e científico de centos hospitalares e universitários. A natureza especial da atividade que esses agentes exercem impõe maior flexibilidade no seu recrutamento.

A segunda exceção corresponde à ocupação de empregos permanentes, quando a natureza das funções ou a necessidade do serviço justificam o recrutamento de agentes não titulares. Isso ocorre tanto na hipótese de inexistência de um corpo de funcionários suscetível de assegurar essas funções, quanto na hipótese de necessidade de conhecimentos téc-

\footnotetext{
18 CHAPUS, René. Droit Administratif General. Tomo II. 9. ed. Paris: Montcherestien, 1996, p. 46.

${ }^{19}$ BERTRAND, Frédérique. Fonction Publique. Revue Française de Droit Administrative. 3 (4) jul./ago. 1987, p. 555.
}

A \& C R. de Dir. Administrativo e Constitucional, Belo Horizonte, ano 5, n. 19, p. 97-113, jan./mar. 2005 
nicos altamente especializados para o desempenho de funções novas na Administração.

Como a segunda exceção prevê situações extremamente vagas, que poderiam dar ensejo ao abuso de recrutamento de agentes pela via da exceção, o legislador previu dois importantes obstáculos à possível fuga da norma geral de nomear apenas funcionários públicos para o exercício de empregos permanentes do Estado: uma duração estritamente limitada do contrato, concluído por três anos, no máximo, e renovável somente uma vez, por igual período, e a determinação por decreto, definindo, por ministério, as categorias concernentes a esse tipo de contratação.

A terceira exceção prevista pela lei $n^{\circ} 83-481$, de 11 de junho de 1983, para a nomeação de agentes não titulares, refere-se a uma necessidade permanente, porém concernente à ocupação de um serviço a tempo incompleto.

Por fim, a quarta exceção corresponde àquelas funções em que os agentes que as substituíram foram recrutados antes de junho de 1983 e não puderam ou não quiseram titularizá-las.

Ocorre que, a despeito da reconhecida prática e, depois, da previsão legal de recrutamento de agentes não titulares na Função Pública francesa, esses agentes mantiveram-se, até o decreto $\mathrm{n}^{\circ} 86-83$, de 17 de janeiro de 1983 (que regulamentou o disposto no artigo 7 da lei de 11 de janeiro de 1984), sem a definição das suas condições gerais.

Todavia, da proteção trazida pelo decreto $n^{\circ} 86-83$, de 17 de janeiro de 1983, ficaram excluídos aqueles agentes recrutados para executar um ato determinado, cuja função mais se refere a uma prestação de serviço do que a uma atividade assalariada. Trata-se de agentes que desempenham tarefas bastante precisas, particulares e facilmente cumpridas por um curto período de tempo, a exemplo de um médico que realiza, a título ocasional, uma visita médica, por conta da Administração, ou do especialista jurídico ao qual se demanda uma consulta sobre um problema específico de Direito.

\subsection{Agentes contratados pelo regime de Direito Privado}

Assim como no Brasil, também existem, na França, certas categorias de agentes que são recrutados por meio de contrato de Direito Privado para o desempenho de Função Pública.

São regidos pelo Direito Privado os agentes contratados para os serviços públicos industriais e comerciais, especialmente o pessoal das 
empresas públicas, ${ }^{20}$ resultantes das nacionalizações de 1946, sendo seus conflitos de interesse apreciados não pela jurisdição administrativa, mas pelo contencioso judiciário (jurisdição comum).

Esse entendimento já havia se dado com a interpretação do acórdão do Tribunal de Conflitos, de 22 de janeiro de 1921, envolvendo a Sociedade Comercial do Oeste Africano, que estabeleceu para o pessoal que trabalhasse nos serviços industriais e comerciais o regime jurídico de Direito Privado.

Também se encontram agentes regidos pelo Direito Privado, de forma mais excepcional ainda, nos serviços administrativos ${ }^{21}$ e nas sociedades de economia mista, decorrentes das privatizações da década de 80 .

Existem, entretanto, algumas exceções à natureza jurídica da relação de trabalho do pessoal das empresas públicas e sociedades de economia mista, como os que trabalham nos serviços de difusão, regidos pela lei de 7 de agosto de 1974, que são, portanto, estatutários.

Laubadère, Venezia e Gaudemet ${ }^{22}$ também citam os casos dos oficiais florestais (L. 23 déc. 1964) e dos agentes dos correios (art. 29 da lei de 2 de julho de 1990).

Igualmente, pode-se citar, como exemplo, o caso dos servidores que trabalhavam na antiga empresa estatal exploradora de serviços de telecomunicações, posteriormente transformada em sociedade anônima (France Telecom), pessoa jurídica de Direito Privado, que tiveram seus direitos estatutários resguardados e protegidos, após a privatização.

\section{Estudo sobre a natureza jurídica do vínculo de trabalho entre o Estado e o agente na França}

\subsection{Regime estatutário ou legal}

O estudo da natureza jurídica do vínculo entre Estado e agente, na relação de trabalho, passa, necessariamente, por dois importantes caminhos:

O primeiro refere-se à preocupação de se saber se a situação é uma situação de Direito Público ou de Direito Privado, enquanto, num segundo momento, deve-se verificar se o agente se encontra submetido a uma situação legal ou a uma situação jurídica subjetiva resultante de um contrato, que o liga à coletividade pública que o emprega.

${ }^{20}$ Com exceção dos diretores e chefes de contabilidade dessas empresas, como se extrai do julgamento de 8 de março de 1957, em que o Conselho de Estado, decidindo o caso Jalenques de Labeau, entendeu se tratar de serviços personalizados e que a natureza jurídica da relação de trabalho depende da natureza do serviço aos quais os agentes estão vinculados.

${ }^{21}$ DEBBASCH, Charles. Sciense Administrative. 4. ed. Paris: Dalloz, 1980, p. 492

22 LAUBADÈRE, André de; VENEZIA, Jean-Claude; GAUDEMET, Yves. Traité de Droit Administratif. Tome 2.

10. ed. Paris: LGDJ, 1995, p. 23 
No que respeita à natureza jurídica da relação de trabalho entre o Estado e os funcionários públicos, por longo tempo, a doutrina francesa e a jurisprudência do Conselho de Estado se debateram em torno da discussão se o vínculo seria legal (estatutário) ou um contrato de Função Pública.

Após a edição do estatuto dos funcionários públicos de 1946, o artigo 5 deste diploma legal pôs fim à controvérsia, eliminando, por completo, a idéia de contrato de Função Pública.

Lembram Laubadère, Venezia e Gaudemet ${ }^{23}$ que, no regime estatutário, o conteúdo da situação do funcionário é fixado de modo geral e impessoal, isto é, por meio de leis e regulamentos, que são os mesmos para todos os funcionários de uma mesma categoria. As convenções particulares passadas entre a Administração e o funcionário ficam, assim, sem valor jurídico.

Outra característica do regime estatutário é que os funcionários dispõem de recursos por excesso de poder contra decisões administrativas contrárias às leis e regulamentos que organizam a sua situação, conforme se entendeu no julgamento Lafage, de 8 de março de 1912. ${ }^{24}$

A terceira característica consubstancia-se no fato de que todos os litígios envolvendo funcionários estatutários, regidos por normas de Direito Público, derrogatório do Direito comum, são, como já se disse, apreciados e julgados pela jurisdição administrativa francesa.

Por derradeiro, e talvez a mais importante de todas as características, a adoção do vínculo de natureza legal implica nas mesmas conseqüências adotadas no Brasil, sobretudo na imposição unilateral de normas disciplinadoras da Função Pública pelo Estado, revogáveis, a qualquer tempo, por força do princípio da supremacia do interesse público sobre o privado, preservando-se apenas os direitos realmente já adquiridos.

Vale salientar que o Brasil também herdou do Direito Administrativo francês a característica de que, nesse tipo de vínculo, o servidor não tem qualquer garantia ou direito adquirido ao regime jurídico existente no momento do seu ingresso no serviço público, como regras especiais para aposentadoria e outros benefícios pecuniários.

Resguardando-se, tão somente, os direitos já implementados e efetivamente adquiridos pelo funcionário, o Estado tem a faculdade de alterar, quando lhe aprouver, as normas estatutárias.

Os agentes regidos pelo regime legal ou estatutário são todos ${ }^{23}$ LAUBADÈRE, André de; VENEZIA, Jean-Claude; GAUDEMET, Yves. Traité de Droit Administratif. Tome 2. 10. ed. Paris: LGDJ, 1995, p. 32.

24 S. 1913, p. 1 concl. Pichat, notas Hauriou.

A \& C R. de Dir. Administrativo e Constitucional, Belo Horizonte, ano 5, n. 19, p. 97-113, jan./mar. 2005 
empossados no cargo por meio de um ato-condição, que representa um ato individual atributivo de uma situação geral e se denomina nomeação.

Laubadère, Venezia e Gaudemet ${ }^{25}$ classificam o ato de nomeação como ato administrativo unilateral afetado a uma condição resolutória, pois depende da aceitação ou recusa dos encargos do cargo pelo agente.

\subsection{Regime contratual}

Ao contrário do regime legal, o regime contratual é aquele em que as obrigações e direitos resultantes da relação de trabalho são estabelecidos por meio de contrato.

Antes do advento do estatuto de 1946, o estatuto de 1941 já admitia a existência de um tipo especial de agentes, ditos contratuais, submetidos a obrigações gerais e beneficiados por garantias gerais da Função Pública, porém recrutados por meio de verdadeiros contratos.

A noção de agente contratado foi concebida pelo Conselho de Estado para certos agentes coloniais e militares iniciantes, a despeito de algumas discussões doutrinárias.

Extraímos da revista Documents d'études, contendo textos reunidos e comentados por Serge Salon e Jean-Charles Savignac, atinentes à Função Pública francesa, que o Conselho de Estado tem, reiteradamente, considerado que o Código do Trabalho não se aplica aos funcionários, salvo disposições contrárias expressas de lei. Podemos, ainda, concluir que aos funcionários não se aplica a possibilidade de recrutamento por qualquer tipo de contrato, seja de Direito Público, seja de Direito Privado, pela premissa básica de que são todos eles regidos pelo regime estatutário. ${ }^{26}$

Resta, então, que apenas os agentes públicos não funcionários e aqueles não considerados agentes públicos podem ser recrutados pela Administração por meio de contrato.

Ocorre que a grande particularidade do Direito Administrativo francês, no tocante ao regime jurídico adotado na Função Pública, reside no fato de ser possível o estabelecimento de contrato de trabalho entre Estado e agente regido pelo Direito Público, com total semelhança aos típicos

\footnotetext{
${ }^{25}$ LAUBADÈRE, André de; VENEZIA, Jean-Claude; GAUDEMET, Yves. Traité de Droit Administratif. Tome 2. 10. ed. Paris: LGDJ, 1995, p. 33

${ }^{26}$ Todavia, se admite na França, consoante as lições de LAUBADÈRE, VENEZIA e GAUDEMET (op. cit., p. 34), a política de contratualização, que se traduz em negociações periódicas entre ministros e agrupamentos sindicais sobre problemas concernentes à carreira desses agentes, tais como remuneração, reclassificação, etc. Essas negociações visam à conclusão de acordos formais que têm aparência de verdadeiras convenções, podendo-se falar em "contratualização" da Função Pública, sem, no entanto, desnaturar a situação estatutária dos funcionários públicos, posto que, após a assinatura, esses acordos são convertidos em medida regulamentar.
}

A \& C R. de Dir. Administrativo e Constitucional, Belo Horizonte, ano 5, n. 19, p. 97-113, jan./mar. 2005 
contratos administrativos, onde as cláusulas são impostas unilateralmente pelo Estado, com a aceitação do agente, que, a seu turno, anui ao contrato.

Nesses contratos de Direito Público, há, ainda, a possibilidade de previsão pelo Estado das chamadas cláusulas exorbitantes, defesas nos contratos privados, mas totalmente aceitas no Direito Público, por força, outrossim, do princípio da supremacia do interesse público sobre o privado. Essas cláusulas, na maioria das vezes, dizem respeito à possibilidade de alteração do contrato, para melhor atendimento ao interesse público pela Administração, e, até mesmo, de rescisão do contrato, sem qualquer direito de indenização ao agente.

Em linha contrária de pensamento, aduz Louis Rolland ${ }^{27}$ que os contratos de trabalho celebrados entre o indivíduo e o Estado na França regidos pelo Direito Administrativo, em razão da possibilidade de a Administração poder rescindir o contrato antes do prazo previsto, garantem direito de indenização ao agente pelo prejuízo advindo.

Dada a proximidade entre o regime contratual de Direito Público e o regime legal, aplicáveis à natureza jurídica do vínculo de trabalho entre o Estado e o agente na França, há autores que defendem que os contratos administrativos celebrados entre o Estado e seus agentes são verdadeiros vínculos estatutários.

Nesse sentido, pontificam os autores Laubadère, Venezia e Gaudemet, ${ }^{28}$ segundo os quais o contrato de Direito Público possui, na verdade, o atributo de uma situação legal e regulamentar, considerando que a autoridade administrativa competente pode, em respeito às disposições legislativas e regulamentares aplicáveis à espécie, fixar e modificar livremente os dispositivos estatutários que regem os agentes de serviços públicos, mesmo contratuais, especialmente aquelas relativas à remuneração, sem a possibilidade de invocação de direito adquirido por tais agentes.

Apesar da incontestável semelhança entre esses dois sistemas, mormente no que diz respeito à possibilidade de alteração unilateral das obrigações e direitos das partes pelo Estado, acreditamos que a diferença deve ser preservada, pois, em se tratando de contrato de Direito Público, não existe propriamente a presença de um estatuto, no sentido de regra geral e abstrata. Esses contratos, ainda que de Direito Público, são celebrados e avençados, tendo-se em vista as peculiaridades de situações e direitos ${ }^{27}$ ROLLAND, Louis. Précis de Droit Administratif. 10. ed. Paris: Dalloz, 1951, p. 78.

${ }^{28}$ LAUBADĖRE, André de; VENEZIA, Jean-Claude; GAUDEMET, Yves. Traité de Droit Administratif. Tome 2. 10. ed. Paris: LGDJ, 1995, p. 34.

A \& C R. de Dir. Administrativo e Constitucional, Belo Horizonte, ano 5, n. 19, p. 97-113, jan./mar. 2005 
subjetivos específicos.

Conforme já mencionado, apenas excepcionalmente, nos casos dos agentes das empresas públicas e sociedades de economia mista prestadoras de serviços industriais e comerciais, a exceção de seus contadores e diretores (e, mais excepcional ainda, em alguns serviços administrativos), se admite a possibilidade de contrato de trabalho, tendo por empregador o Estado, regido pelo Direito Privado.

Ainda assim, há que se ressaltar que, mesmo nesses contratos, a presença do Direito Privado, não chega a ser completa, em razão de impossibilidade de escape total do regime jurídico-administrativo pela Administração Pública.

\section{Conclusão}

Fortemente influenciado pelo Direito Administrativo francês, no Direito brasileiro, percebe-se, no que se refere à classificação e à natureza jurídica da relação de trabalho entre o Estado e seus agentes, inúmeras tendências verificadas na França.

No aspecto concernente à classificação, constatamos uma uniformidade entre os autores franceses, ainda não alcançada no Brasil.

Porém, enquanto para os franceses a noção de agente público compreende os indivíduos que mantém relação de trabalho regida pelo Direito Público, a nossa tem a amplitude de considerar não só os regidos pelo Direito Privado, como também os particulares em colaboração com a Administração Pública e, até mesmo, os agentes políticos.

Já com relação à natureza do vínculo, percebemos a semelhança da previsão tanto do vínculo estatutário, quanto contratual, nos dois sistemas. A grande peculiaridade do sistema francês refere-se à existência de agentes públicos regidos por contratos de Direito Público, com as características de típicos contratos administrativos, com as chamadas cláusulas exorbitantes, conforme ressaltamos anteriormente.

O tratamento dado ao regime estatutário se apresenta idêntico nos dois países, com a exceção da possibilidade recente de negociação coletiva (concertação) entre agentes públicos e ministros, sobre questões de remuneração e outras próprias da carreira, o que, no nosso entendimento, se apresenta bastante benéfico, inclusive, com o objetivo de se evitar as constantes greves no serviço público, em respeito ao princípio da continuidade do serviço público, sendo as aspirações dos agentes, nesses casos, tanto inevitáveis, quanto, na maioria das vezes, legítimas. 
Ressalta-se, por fim, a tendência incontornável do Direito Administrativo francês de aproximar, ao máximo, não só o regime jurídico, mas também o próprio estatuto de seus funcionários, aos demais Estados membros da União Européia, mormente após a recém promulgada Constituição Européia.

O Direito comunitário, inevitavelmente, exigirá uma definição de Função Pública, no mínimo, relativamente semelhante nos Estados membros da União Européia, a despeito de o Tratado de Roma excluir os empregos da Administração Pública da exigência de livre circulação de pessoas. ${ }^{29}$

\section{Referências}

BERTRAND, Frédérique. Fonction Publique. Revue Française de Droit Administrative. 3 (4) Jul.-Ago. 1987.

CHAPUS, René. Droit Administratif General. Tomo II. 9. ed. Paris: Montcherestien, 1996.

DEBBASCH, Charles. Sicense Administrative. 4. ed. Paris: Dalloz, 1980.

DERRIDJ, Laura. Le Recours aux Agents non Titulaires de la Fonction Publique Territoriale: Peut-il Encore Exister un Príncipe du Contrat à Durée Déterminée? Revue Française de Droit Administrative, Jan.-Fev. 2003.

JORION, Benoit. Le Príncipe de Parité entre Fonctions Publiques: un Príncipe peau de Chagrin. Revue Française de Droit Administrative. 14 (2) Mar.-Abr.1998.

LAUBADÈRE, André de; VENEZIA, Jean-Claude; GAUDEMET, Yves. Traité de Droit Administratif. Tome 2. 10. ed. Paris: LGDJ, 1995.

ROLLAND, Louis. Précis de Droit Administratif. 10. ed. Paris: Dalloz, 1951.

SALON, Serge; SAVIGNAC, Jean-Charles. La Notion de Fonction Publique. Documents d'études. N. 2.01. Édition 2002.

Informação bibliográfica deste texto, conforme a NBR 6023:2002 da Associação Brasileira de Normas Técnicas (ABNT):

SILVEIRA, Raquel Dias da. A natureza jurídica da relação de trabalho entre o Estado e seus agentes no Direito Administrativo francês. A $\mathcal{E}^{2}$ C Revista de Direito Administrativo e Constitucional, Belo Horizonte, ano 5, n. 19, p. 97-113, jan./mar. 2005.

\footnotetext{
${ }^{29}$ Apenas a título exemplificativo, a França, para atender às exigências da comunidade, já foi obrigada a promulgar a lei de 26 de julho de 1991, para possibilitar o acesso a cargos e empregos públicos a indivíduos de outras nacionalidades européias, exceto para cargos relativos à segurança nacional.
} 